\title{
Review Article \\ The Role of Intestinal Microbiota in Acute Graft-versus-Host Disease
}

\author{
Yuanyuan Chen, ${ }^{1}$ Ye Zhao, ${ }^{2}$ Qiao Cheng, ${ }^{1}$ Depei Wu, ${ }^{2}$ and Haiyan Liu ${ }^{1,2}$ \\ ${ }^{1}$ Laboratory of Cellular and Molecular Tumor Immunology, Jiangsu Key Laboratory of Infection and Immunity, \\ Institutes of Biology and Medical Sciences, Soochow University, Suzhou 215123, China \\ ${ }^{2}$ Cyrus Tang Hematology Center, Department of Hematology, Jiangsu Institute of Hematology, \\ Collaborative Innovation Center of Hematology, The First Affiliated Hospital of Soochow University, Suzhou 215006, China
}

Correspondence should be addressed to Haiyan Liu; hliu@suda.edu.cn

Received 25 December 2014; Revised 16 February 2015; Accepted 28 February 2015

Academic Editor: Pedro Giavina-Bianchi

Copyright (C) 2015 Yuanyuan Chen et al. This is an open access article distributed under the Creative Commons Attribution License, which permits unrestricted use, distribution, and reproduction in any medium, provided the original work is properly cited.

\begin{abstract}
The mammalian intestinal microbiota is a complex ecosystem that plays an important role in host immune responses. Recent studies have demonstrated that alterations in intestinal microbiota composition are linked to multiple inflammatory diseases in humans, including acute graft-versus-host disease (aGVHD). aGVHD is one of the major obstacles in allogeneic hematopoietic stem cell transplantation (allo-HSCT), characterized by tissue damage in the gastrointestinal (GI) tract, liver, lung, and skin. Here, we review the current understanding of the role of intestinal microbiota in the control of immune responses during aGVHD. Additionally, the possibility of using probiotic strains for potential treatment or prevention of aGVHD will be discussed.
\end{abstract}

\section{Introduction}

The mammalian gastrointestinal (GI) tract harbors a dense and diverse microbial community, which is composed primarily of bacteria but also includes fungi, archaea, and viruses; collectively, these are referred to as the intestinal microbiota [1]. These microorganisms establish symbiotic relationships with their hosts, playing crucial roles in the digestion of food and exerting a considerable influence on the physiological, metabolic, nutritional, and immunological state of the host [2-4]. Recent studies have demonstrated that alterations in the composition of intestinal microbiota are linked to multiple metabolic and inflammatory diseases in humans, including obesity, inflammatory bowel disease (IBD), colorectal cancer, allergy, type 2 diabetes, liver cirrhosis, rheumatoid arthritis, and neurodevelopmental disorders [5-12]. These associations raise fundamental questions regarding the immunomodulatory mechanisms by which components of the intestinal microbiota and their metabolites influence resistance or susceptibility to a broad range of clinically important diseases.

Allogeneic hematopoietic stem cell transplantation (alloHSCT) is the only curative therapy for hematologic malignant tumors, bone marrow failure, and congenital metabolic disorders. However, the development of acute graft-versushost disease (aGVHD) limits the success of allo-HSCT and is fatal to approximately $15 \%$ of transplant recipients $[13,14]$. aGVHD results from an immunological attack on target recipient organs and tissues (such as the skin, liver, lung, and GI tract) by donor allogeneic $T$ cells that are transferred along with the allograft. The development and severity of aGVHD in transplant recipients depend on factors such as recipient age, toxicity of the conditioning regimen, hematopoietic graft source, and aGVHD prophylaxis approaches [15]. Steroids are the first line of treatment, but patients with steroidrefractory aGVHD have a dismal outcome, with long-term mortality rates that can reach $90 \%$ [16]. Recent studies have demonstrated a close relationship between intestinal microbiota composition and the severity of aGVHD [17-19].

\section{Altered Intestinal Microbiota Composition and Diversity Associated with aGVHD}

For many years, our understanding of the composition of mammalian intestinal microbiota depended on culturing 
and identifying commensal microorganisms. However, this approach is insufficient to catalog intestinal microbial species because the majority of intestinal bacteria cannot be cultured by currently available methods [20]. The emergence of new molecular profiling techniques, such as $16 \mathrm{~S}$ rRNA sequencebased microbial identification and high-throughput sequencing analysis, has led to a revolution in the understanding of the intestinal microbiota by allowing culture-independent analysis of microbial community composition [21].

The human gut harbors approximately one hundred trillion microbes, which is ten times the number of human cells in the body [22]. Their combined genomes contain more than five million genes, outnumbering the human genetic potential by two orders of magnitude [23]. Several phyla of bacteria constitute the bulk of the human intestinal microbiota. The most abundant phyla in the human intestine are Firmicutes and Bacteroidetes, which constitute over 90\% of the human intestinal microbes. The Firmicutes consist primarily of bacteria belonging to the Clostridia class and include a subset of Bacilli (Bacillaceae, Enterococcaceae, and Lactobacillaceae), which are capable of oxidizing organic sugars via fermentation to produce large amounts of lactic acid and carbon dioxide [24,25]. Members of the gut bacteria belonging to the Bacteroidetes are represented by several Bacteroides species, including B. acidifaciens, B. sartorii, and $B$. uniformis. The remainder of the commensal bacteria, accounting for less than $10 \%$ of the total population, belongs to the phyla Proteobacteria, Fusobacteria, Actinobacteria, Verrucomicrobia, Cyanobacteria, and TM7. These bacteria are capable of successfully competing with members of the Firmicutes and Bacteroidetes in a strict anaerobic environment, such as the colon $[26,27]$.

The importance of the intestinal microbiota to host health is highlighted by alterations in community composition in metabolic and inflammatory diseases, such as obesity and IBD $[5,6]$. The impact of the gut microflora on aGVHD has been shown to be highly significant (Table 1). Earlier studies in mice showed that symptoms of aGVHD could be reduced with antibiotics and transplantation in germ-free conditions $[28,29]$. One recent study showed how intestinal microbiota influences aGVHD progression following allogeneic bone marrow transplantation (allo-BMT) [19]. Analysis of the microbiota composition indicated that recipient mice that developed aGVHD had a dramatic loss of bacterial diversity and a distinct composition compared with recipient mice that did not develop aGVHD. In mouse models of aGVHD, there is marked expansion of Lactobacillus johnsonii and a decrease in both Clostridiales and in other members of the phylum Firmicutes in the ileum. To determine the connection between $L$. johnsonii and aGVHD, the recipient mice were treated with antibiotics and then gavaged with L. johnsonii prior to allo-BMT. Antibiotic-treated mice showed a loss of Clostridiales and an emergence of Enterococcus spp., which was associated with exacerbated aGVHD [30]. In contrast, mice reintroduced with $L$. johnsonii showed no expansion of Enterococcus spp. and did not experience increased aGVHD lethality or pathology. These results suggest that L. johnsonii may reduce aGVHD severity by preventing the expansion of Enterococcus spp. A clinical research study elucidated variations in the intestinal microbiota of 31 patients receiving allogeneic HSCT [31]. The result of metagenomic analysis showed that patients had a predominance of commensal bacteria at the time of admission. After transplantation, a relative shift toward Enterococci was observed, and this shift was particularly prominent in patients that developed subsequently active gastrointestinal aGVHD. Another clinical study revealed that the diversity of intestinal microbiota at engraftment is an independent predictor of mortality in allo-HSCT recipients. Mortality outcomes were significantly worse in patients with lower intestinal diversity [32].

\section{Intestinal Barrier Damage and LPS-Induced Septicemia during aGVHD}

Scientists have described several requirements for aGVHD development. First, the graft infused into the patient must contain immunological cells, such as mature T cells. Second, the recipient must be immunocompromised and cannot reject cells from the donor. Third, there are immunologic disparities between the recipient and the donor tissue cells. It is accepted that the development of aGVHD can be conceptualized as a three-stage process [15, 36]. First, antigen-presenting cells (APCs) are activated. Underlying diseases, previously administered therapies and the HSCT conditioning regimen can damage host tissues, resulting in the production of "danger signals," such as proinflammatory cytokines, chemokines, MHC antigens, and costimulatory molecules on host APCs. Second, donor $\mathrm{T}$ cells proliferate and differentiate in response to activated host APCs. Additional inflammatory cytokines are then released. Finally, a complex cascade is triggered. Both cellular mediators, such as cytotoxic lymphocytes (CTLs) and NK cells, and inflammatory factors, such as tumor necrosis factor alpha (TNF- $\alpha$ ), interferon gamma (IFN- $\gamma$ ), and interleukin-1 (IL-1), can cause the destruction of the target tissue, typically the skin, liver, and gut.

It has been proposed that the GI tract may be particularly critical at the initial stage. Both total body irradiation (TBI) and high-intensive chemotherapy as part of the conditioning regimen can reduce or eliminate tumor load and cause sufficient immunosuppression to prevent graft rejection. However, such treatments may also stimulate host tissues to secrete inflammatory cytokines, such as TNF- $\alpha$ and IL-1, and their direct influence on epithelial cells of the GI tract allows for the translocation of intestinal microbes and their by-products, including lipopolysaccharide (LPS) and peptidoglycan, into the systemic circulation (Figure 1).

The symbiotic nature of the intestinal host-microbial relationship is dependent on limiting bacterial penetration of host tissues. Controlling bacterial interactions with the intestinal surface is an important strategy for minimizing bacterial translocation [37]. The intestinal epithelial surface is the primary interface between the gut bacteria and deeper tissues. Given the enormous numbers of commensal microbes and the persistent invasion of pathogens, it is important that the host immune system monitors and regulates microbial interactions with the intestinal surface [38]. 
TABLE 1: Effect of the intestinal microbiota on GVHD.

\begin{tabular}{|c|c|c|c|}
\hline Host & Outcome & Possible mechanisms & Refs. \\
\hline Mouse & $\begin{array}{l}\text { Oral administration of Lactobacillus rhamnosus } \\
\text { GG (LGG) before and after transplantation results } \\
\text { in improved survival and reduced aGVHD }\end{array}$ & $\begin{array}{l}\text { Mice treated with LGG have a reduced } \\
\text { translocation of enteric bacteria }\end{array}$ & {$[17]$} \\
\hline Mouse & $\begin{array}{l}\text { Loss of physiologic diversity among the intestinal } \\
\text { microbiota and the overwhelming expansion of } \\
\text { Escherichia coli which caused septicemia }\end{array}$ & $\begin{array}{l}\text { Paneth cells are targeted by GVHD, } \\
\text { resulting in marked reduction in the } \\
\text { expression of } \alpha \text {-defensins }\end{array}$ & {$[18]$} \\
\hline Mouse & $\begin{array}{l}\text { Loss of overall diversity of gut microbiota. } \\
\text { Eliminating Lactobacillales from the mice before } \\
\text { BMT aggravated GVHD, whereas reintroducing } \\
\text { Lactobacillus johnsonii mediated significant } \\
\text { protection against GVHD }\end{array}$ & $\begin{array}{l}\text { L. johnsonii reduced GVHD severity by } \\
\text { prevention of Enterococcus expansion }\end{array}$ & {$[19]$} \\
\hline Mouse & $\begin{array}{l}\text { Increased bacterial translocation and serum } \\
\text { lipopolysaccharide (LPS) levels were detected } \\
\text { after TBI }\end{array}$ & $\begin{array}{l}\text { Neutrophil granulocytes recruited upon } \\
\text { translocation of intestinal bacteria } \\
\text { enhance GVHD via tissue damage }\end{array}$ & {$[33]$} \\
\hline Mouse & $\begin{array}{l}\text { The inflammatory responses in intestinal GVHD } \\
\text { (iGVHD) were accompanied by gut flora shifts } \\
\text { towards Enterobacteria, Enterococci, and } \\
\text { Bacteroides/Prevotella spp. }\end{array}$ & $\begin{array}{l}\text { iGVHD development is mediated by } \\
\text { MyD88/TLR9-dependent bacterial } \\
\text { sensing }\end{array}$ & [34] \\
\hline Human & $\begin{array}{l}\text { Successful total gastrointestinal decontamination } \\
\text { (GID) of the graft recipient prevents moderate to } \\
\text { severe acute GVHD }\end{array}$ & $\begin{array}{l}\text { Prevention of intestinal microorganisms } \\
\text { translocation }\end{array}$ & {$[35]$} \\
\hline Human & $\begin{array}{l}\text { After transplantation, a relative shift toward } \\
\text { Enterococci was observed, especially in patients } \\
\text { that developed subsequently or suffered from } \\
\text { active GI GVHD }\end{array}$ & $\begin{array}{l}\text { Early microbiome shifts may affect } \\
\text { intestinal inflammation in the setting of } \\
\text { allogeneic SCT }\end{array}$ & {$[31]$} \\
\hline Human & $\begin{array}{l}\text { Mortality outcomes were significantly worse in } \\
\text { patients with lower intestinal tract bacterial } \\
\text { diversity }\end{array}$ & $\begin{array}{l}\text { Intestinal microbiota may be an } \\
\text { important factor in the success or failure } \\
\text { in allo-HSCT }\end{array}$ & {$[32]$} \\
\hline
\end{tabular}

The intestinal surface maintains an intact barrier through formation of complex protein-protein networks that firmly join together via tight junctions [39]. In HSCT, both TBI and chemotherapy can cause intestinal mucosa damage. Following this, intestinal bacteria may translocate into deeper tissues from the damaged GI tract and cause infection and septicemia [40]. In a mouse model of aGVHD, serious impairment of intestinal barrier function in the jejunum was detected, with increased permeability and morphological changes owing to both decreased protein expression and altered localization of the tight junction protein occluding [41]. There is a significant relationship between gut microbiota and intestinal radiosensitivity. In a mouse model of TBI-BMT, germ-free mice were markedly resistant to lethal radiation enteritis [42]. Several commensal bacteria or their components have the ability to protect intestinal mucosal tissue from irradiation damage. Bacteria-derived flagellin pretreatment protected mice from radiation-induced intestinal mucosal injury and apoptosis via a Toll-like receptor 5 (TLR5)-dependent mechanism [43]. In a human trial, patients taking the probiotic mixture VSL\#3 (a mixture of eight probiotic strains) experienced radiation-induced diarrhea less frequently than patients taking a placebo in a double-blinded study [44]. Another study showed that a Lactobacillus rhamnosus GG- (LGG-) derived soluble protein, p40, ameliorates intestinal injury and colitis, reduces apoptosis, and preserves barrier function by transactivation of the EGF receptor (EGFR) in intestinal epithelial cells [45].

The Paneth cell is an intestinal epithelial cell that plays a key role in limiting bacterial penetration into host tissues. Paneth cells secrete the majority of antimicrobial proteins produced by the small intestine. These cells have a much longer half-life than other cells found in the small intestine [46]. Paneth cells can secrete a number of microbicidal proteins, including $\alpha$-defensins, which selectively kill pathogens, while preserving commensals. When Paneth cells sense bacterial signals, they react by discharging their microbicidal granule contents into the gut lumen [47]. Therefore, Paneth cells are critical to the immune response to pathogens and the maintenance of a noninflammatory commensal flora in the small intestine. Current studies show that Paneth cells are targeted by aGVHD, resulting in a substantial loss of Paneth cells in the intestine and marked reduction in the expression of $\alpha$-defensins in recipients with aGVHD. Restriction fragment length polymorphism (RFLP) of intestinal microbial communities showed loss of physiologic diversity among the microbiota and the overwhelming expansion of a rare bacterium. 16S rRNA gene sequencing demonstrated that this peak was almost certainly due to the presence of Escherichia coli in the intestine of recipients suffering from aGVHD [18]. 


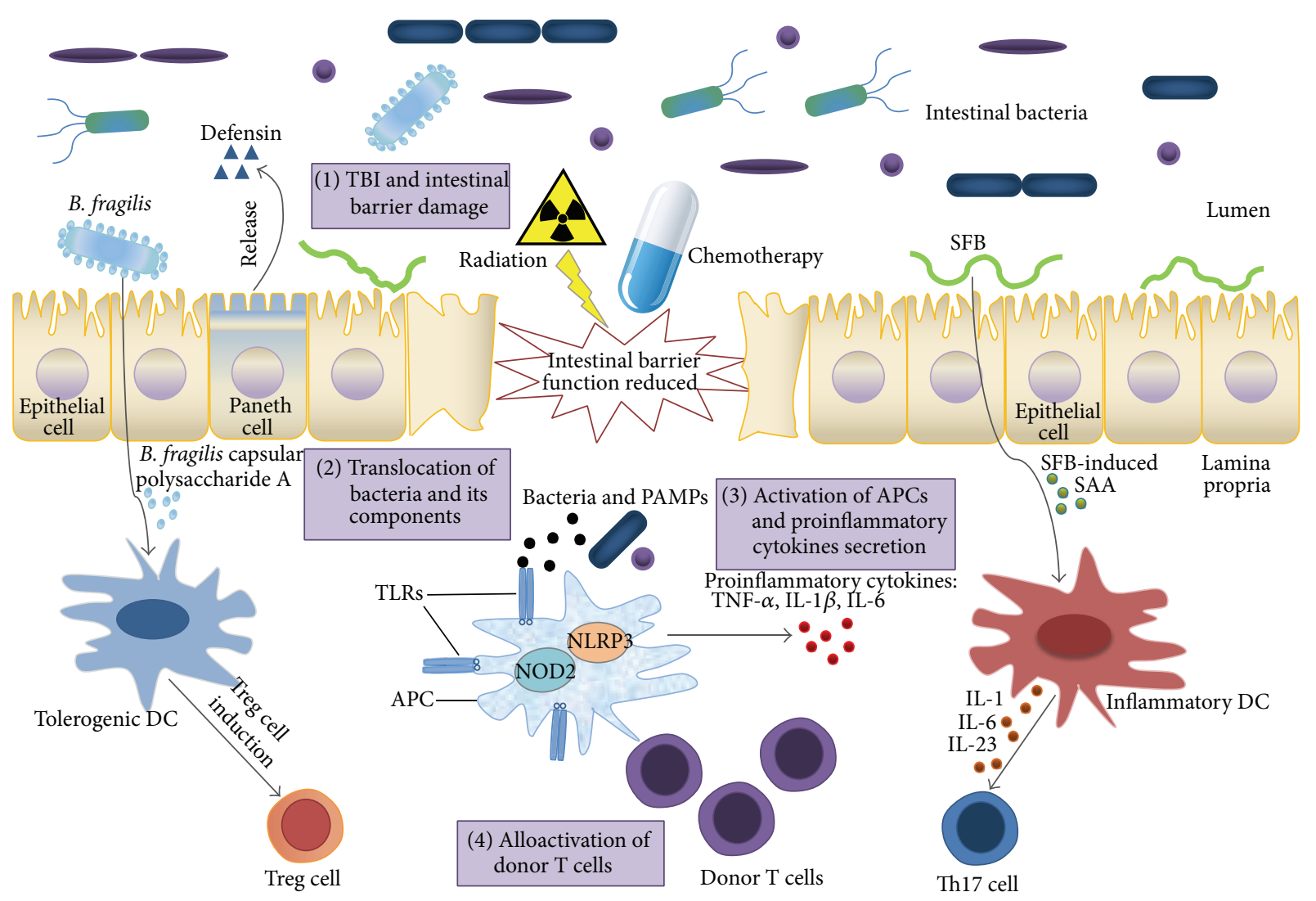

FIGURE 1: Schematic of the role of microbiota in graft-versus-host disease in the gut. Under normal conditions, the intestinal epithelial surface maintains an intact barrier function that prevents bacterial invasion into deeper host tissues. Paneth cells secrete several microbicidal proteins, including $\alpha$-defensins, which selectively kill pathogenic bacteria. Bacteroides fragilis-derived TLR capsular polysaccharide A can promote the induction of Treg cells. Segmented filamentous bacteria (SFB) induce production of serum amyloid A (SAA) in the gut, and SAA acts on dendritic cells (DCs) to promote Thl7 cell differentiation. After total body irradiation (TBI) and chemotherapy as part of the conditioning regimen, the integrity of the intestinal surface is decreased. Intestinal bacteria and their components (pathogen-associated molecular patterns, PAMPs) translocate to the lamina propria and are recognized by Toll-like receptors (TLRs) in host antigen-presenting cells (APCs). Activated APCs secrete proinflammatory cytokines and prime donor T cells, which aggravate acute GVHD.

Another clinical study showed that enumeration of duodenal Paneth cells is a readily available index of disease severity that provides important information regarding aGVHD prognosis [48].

aGVHD and related infections are major obstacles to HSCT. Septicemia is the most life-threatening infection following allogeneic HSCT, and gram-negative bacteria are the most dominant pathogens of septicemia. aGVHD is regarded as one of the major predisposing factors for the development of septicemia. LPS can enter the circulation through the impaired mucosal barrier after the conditioning regimen. In experimental studies, the proinflammatory potency of LPS varies from bacterial species to species. Probiotic microorganisms have been shown to alter the composition of the intestinal microflora and thereby mediate anti-inflammatory effects. Modifying the intestinal microbiota by oral administration of LGG before and after transplantation resulted in improved survival and reduced aGVHD. Furthermore, subculture of mesenteric lymph nodes revealed a reduced translocation of enteric bacteria [17].

\section{Connections among Intestinal Microbiota, Innate Immune Receptors, and T Cell Differentiation during aGVHD}

Connections between pathogen-associated molecular patterns (PAMPs) and pathogen recognition receptors (PRRs) control adaptive immune responses in inflammatory disorders, including aGVHD. Intestinal bacteria and their components are recognized by PRRs in antigen-presenting cells (APCs). The stimulation of PRRs leads to transcription of inflammatory genes and upregulation of proinflammatory cytokines and class II and costimulatory molecules, resulting in local tissue inflammation and migration of leukocytes [49].

Intestinal mucosal surfaces are rich in resident innate immune cells, such as macrophages and dendritic cells (DCs). Signaling through PRRs regulates the activity of DCs, leading to phagocytosis, chemokine receptor expression, cytokine secretion and migration from peripheral tissue to draining lymph nodes, and antigen presentation (Figure 1). Several TLRs have been described to recognize different 
PAMPs, including gram-positive bacteria-derived lipoproteins (TLR2), gram-negative bacteria-derived LPS (TLR4), bacterial flagellin (TLR5), RNA (TLR3, TLR7, and TLR8), cytosine-phosphorothioate-guanine (CpG) DNA (TLR9), profilin (TLR11, TLR12), and bacterial $23 \mathrm{~S}$ ribosomal RNA (TLR13) [50,51]. TLR downstream signaling activates a complex signaling cascade, eventually leading to host resistance against pathogens by increased production of cytokines, chemokines, adhesion molecules, and antimicrobial peptides, as well as to enhanced antigen presentation by APCs. PAMPs are recognized not only by TLRs but also by nucleotidebinding oligomerization domain- (NOD-) like receptors (NLRs). NLRs include proteins such as NALPs, NOD1, and NOD2, which are involved in the secretion of inflammatory cytokines, such as IL-1 $\alpha$ and IL-18 [52].

As recognized molecular patterns of invading and resident microbes, TLRs are fundamental to controlling intestinal tissue homeostasis in studies that involve intestinal epithelial cell damage. In experimental aGVHD, TLRs appear to have a significant role in disease outcomes. In models of HSCT, TLR9 ${ }^{-1-}$ transplant recipient mice have enhanced survival compared to wild type mice [53]. However, the role of TLR4 in aGVHD is still unclear, with conflicting findings in different studies $[54,55]$. Evaluation of the expression of TLRs on T lymphocytes and monocytes in 34 patients showed that levels of TLR5 on monocytes and T lymphocytes are positively correlated with aGVHD, whereas levels of TLR1 and TLR9 are negative predictors [56].

The pathophysiology of aGVHD is a multistep process that eventually results in T helper 1-driven (Th1-driven) tissue damage. Recently, increasing evidence indicates the involvement of T helper 17 (Th17) and regulatory T cells (Tregs) in aGVHD pathogenesis [57]. One clinical study showed that in situ quantification of the Th17/Treg ratio was a specific marker of human aGVHD [58]. Murine experimental studies provide inconsistent results on the role of Th17 in aGVHD [59-61]. In contrast, Treg contributes to tolerance acquisition to donor antigen in solid organ transplantation and protects the development of fatal aGVHD in murine model [62].

The homeostasis of steady-state mucosal $\mathrm{T}$ cell subsets is controlled by signals from various components of the intestinal microbiota $[63,64]$. Treg and Th17 cells are the most abundant lamina propria $\mathrm{CD} 4^{+} \mathrm{T}$ cell subsets at steady state. Tregs are crucial in inhibiting excessive inflammatory responses toward intestinal bacteria $[65,66]$. Th17 cells are characterized by the production of IL-17 and other effector cytokines, such as IL-17F and IL-22. Th17 cell-derived cytokines function as important activators of innate immune mechanisms, such as recruitment of neutrophils and induction of antimicrobial peptide production from epithelial cells. Th17 cells also play crucial roles in mucosal defense against bacteria and fungi [67]. Treg and Th17 cells have reciprocal functions in regulation of intestinal microbiota. Treg and Th17 cell numbers in the gut are controlled by signals from different species of the commensal microbiota $[68,69]$. Colonic Treg cells are induced by bacteria belonging to group IV and XIVa Clostridia, and small intestinal Thl7 cells are induced by segmented filamentous bacteria (SFB) [70-72].

\section{Probiotics and Their Potential Application in the Treatment of aGVHD}

Patients undergoing allo-HSCT have a substantially increased risk of bacterial, fungal, and viral infection. Multiple approaches to decrease the risk of infections after HSCT have been explored, including laminar airflow housing, the use of antibiotics, and prophylactic antiviral and antifungal therapies [73]. Antibiotic resistance in pathogenic bacteria has been an increasing threat to human health during the last decade, and it is widely accepted that the antibiotic resistance development and spread in microbes can be largely attributed to the abuse and misuse of antibiotics [74]. In addition, breakdown of the normal microbial community by antibiotic use increases the risk of pathogen infection and the overgrowth of harmful disease. Clostridium difficile infection (CDI) is the most common cause of severe diarrhea and occurs with increased frequency after broad-spectrum antibiotic treatment $[75,76]$. Results from a retrospective study showed that CDI is strongly associated with aGVHD and increased nonrelapse mortality in allo-HSCT patients [77]. In recent years, fecal microbiota transplantation (FMT) has emerged as an efficacious method for the treatment of CDI $[78,79]$. FMT refers to infusion of a fecal suspension from a healthy individual into the GI tract of a patient to restore healthy intestinal microbiota and cure disease. However, there is risk associated with FMT. This is because fecal suspension contains harmful bacteria, viruses, and parasites. An alternative solution to this problem is to screen some beneficial bacteria from stool and only infuse these bacteria as a cocktail into the GI tract [80, 81].

Probiotics are live microorganisms, which when administered in adequate amounts confer a health benefit to the host. Probiotic strains are derived from fermented foods, beneficial commensals, or the environment. A broad range of consumer products containing probiotic microbes is currently available. Various animal and human studies have demonstrated that some probiotic strains can successfully modify the mucosal immune response due to species and strain specificity of the probiotics $[82,83]$. The most commonly used probiotics are Bifidobacterium, Bacillus, and the lactic acid bacteria (LAB), including genus Lactobacillus and Streptococcus [84]. Lactobacillus rhamnosus ATCC 53103, isolated from a healthy human intestinal commensal, is one of the most widely used and well-documented probiotic strains [17, 45, 85-87]. Some of the beneficial impacts of probiotics have been scientifically documented, and three main categories of probiotics contributing to host health have been described [83, 88, 89]. First, certain probiotics can exclude or inhibit pathogens. Second, probiotics can enhance the function of the intestinal epithelial barrier by modulating various signaling pathways, inducing mucus and antimicrobial peptide production, enhancing tight junction functioning, and preventing apoptosis. Third, probiotics can modulate host immune responses, resulting in both local and systemic effects.

The rationale for using probiotics to treat gastrointestinal disorders is supported by several clinical studies. In one study, ingestion of Bifidobacterium infantis 35624 was shown to alleviate symptoms of irritable bowel syndrome 
(IBS) associated with normalization of the ratio of antiinflammatory to proinflammatory cytokines [90]. To assess the effects of probiotics in diarrhea, a meta-analysis that included 63 studies $(n=8014)$ was carried out; the results showed that probiotic strains appear to be safe and have clear beneficial effects in shortening the duration and reducing stool frequency in acute infectious diarrhea [91]. Animal models indicate the close connection between gut microbiota and IBD, and several kinds of probiotics were evaluated in human clinical trials [92, 93]. Escherichia coli Nissle 1917 shows efficacy and safety in maintaining a remission equivalent in patients with ulcerative colitis [94]. Another clinical study evaluated the impact of VSL\#3 on maintenance of remission. The once daily high dose probiotic VSL\#3 is effective in maintaining antibiotic-introduced remission for at least one year in patients with recurrent or refractory pouchitis [95].

There are several bottlenecks that need to be overcome before probiotics can be applied in clinical treatment. One important limitation is the delivery of viable cells to the lower GI tract without a significant loss of cell viability and metabolic features through the harsh conditions of the stomach [96]. In addition, compared to animal models, a major challenge for understanding the interactions between intestinal microbiota and human hosts is the heterogeneity of microbial composition that can colonize the intestine. Different components of microbiota can have very different effects on the host, and the composition of microbial communities can be influenced by a variety of factors, including diet, antibiotic therapy, and environmental exposure to microbes $[97,98]$.

\section{Conclusions and Future Perspectives}

An increasing number of studies have identified an important interaction between intestinal microbiota and mammalian host health and disease. It is clear that microbiota can affect disease progression in several experimental animal models. Recent evidence has demonstrated that specific species of intestinal bacteria appear to be specialized in their ability to induce particular immune cell subsets. Probiotic bacteria can modulate immune responses to promote health by altering the composition of intestinal microbiota. Manipulation of the intestinal microbiota through probiotics or their components holds great promise for the treatment of inflammatory diseases, including aGVHD.

Despite some notable successes from probiotics trials, there are numerous obstacles to overcome before probiotic strains can be utilized as aGVHD therapeutics. First, most of the probiotics are species or strain specific. Thus, they should be tested in vitro and then evaluated for their suitability and efficacy in vivo. Only a few probiotic strains have been tested in mouse aGVHD models to date. Hence, there remains a pressing need to screen for probiotic strains that display more remarkable therapeutic responses to aGVHD. Second, although changes in microbiota associated with aGVHD progression are apparent, it is unknown which exact components of the microbiota are responsible for aggravating or ameliorating aGVHD. Therefore, monitoring intestinal microbiota changes of patients before and after aGVHD is of vital significance. Third, the association of intestinal microbiota with aGVHD has become evident. However, causality of aGVHD in response to probiotic-induced microbiota changes still has not been demonstrated. Along with research on screening for safe and effective probiotic strains moving towards increasing profundity, more attention should be focused on the immune mechanisms governing probiotic effects in aGVHD. Several creative therapeutic methods might originate from a better understanding of the relationship among probiotic strains, intestinal microbiota, and immune regulation during aGVHD.

\section{Conflict of Interests}

The authors declare that they have no conflict of interests.

\section{Authors' Contribution}

Yuanyuan Chen and Ye Zhao contributed equally to this work.

\section{Acknowledgments}

This work has been supported by grants from National Natural Science Foundation of China (81273268, 81102271), the project funding from Suzhou city (SWG0904, SZS201109), Priority Academic Program Development of Jiangsu Higher Education Institutions, Qing Lan Project of Jiangsu Province, Jiangsu Provincial Innovative Research Team, and Program for Changjiang Scholars and Innovative Research Team in University (IRT1075).

\section{References}

[1] C. A. Lozupone, J. I. Stombaugh, J. I. Gordon, J. K. Jansson, and R. Knight, "Diversity, stability and resilience of the human gut microbiota," Nature, vol. 489, no. 7415, pp. 220-230, 2012.

[2] H. J. Flint, K. P. Scott, P. Louis, and S. H. Duncan, "The role of the gut microbiota in nutrition and health," Nature Reviews Gastroenterology and Hepatology, vol. 9, no. 10, pp. 577-589, 2012.

[3] J. K. Nicholson, E. Holmes, J. Kinross et al., "Host-gut microbiota metabolic interactions," Science, vol. 336, no. 6086, pp. 1262-1267, 2012.

[4] L. V. Hooper, D. R. Littman, and A. J. Macpherson, "Interactions between the microbiota and the immune system," Science, vol. 336, no. 6086, pp. 1268-1273, 2012.

[5] G. Musso, R. Gambino, and M. Cassader, "Interactions between gut microbiota and host metabolism predisposing to obesity and diabetes," Annual Review of Medicine, vol. 62, pp. 361-380, 2011.

[6] M. Tong, X. Li, L. W. Parfrey et al., "A modular organization of the human intestinal mucosal microbiota and its association with inflammatory bowel disease," PLoS ONE, vol. 8, no. 11, Article ID e80702, 2013.

[7] J. C. Arthur and C. Jobin, “The struggle within: microbial influences on colorectal cancer," Inflammatory Bowel Diseases, vol. 17, no. 1, pp. 396-409, 2011. 
[8] A. T. Stefka, T. Feehley, P. Tripathi et al., "Commensal bacteria protect against food allergen sensitization," Proceedings of the National Academy of Sciences of the USA, vol. 111, no. 36, pp. 13145-13150, 2014.

[9] J. Qin, Y. Li, Z. Cai et al., "A metagenome-wide association study of gut microbiota in type 2 diabetes," Nature, vol. 490, no. 7418, pp. 55-60, 2012.

[10] N. Qin, F. Yang, A. Li et al., "Alterations of the human gut microbiome in liver cirrhosis," Nature, vol. 513, no. 7516, pp. 5964, 2014.

[11] J. U. Scher, A. Sczesnak, R. S. Longman et al., "Expansion of intestinal Prevotella copri correlates with enhanced susceptibility to arthritis," Elife, vol. 2, Article ID e01202, 2013.

[12] E. Y. Hsiao, S. W. McBride, S. Hsien et al., "Microbiota modulate behavioral and physiological abnormalities associated with neurodevelopmental disorders," Cell, vol. 155, no. 7, pp. 14511463, 2013.

[13] J. L. Ferrara, J. E. Levine, P. Reddy, and E. Holler, "Graft-versushost disease," The Lancet, vol. 373, no. 9674, pp. 1550-1561, 2009.

[14] W. D. Shlomchik, "Graft-versus-host disease," Nature Reviews Immunology, vol. 7, no. 5, pp. 340-352, 2007.

[15] B. R. Blazar, W. J. Murphy, and M. Abedi, "Advances in graft-versus-host disease biology and therapy," Nature Reviews Immunology, vol. 12, no. 6, pp. 443-458, 2012.

[16] M. C. Pasquini, Z. Wang, M. M. Horowitz, and R. P. Gale, “2010 report from the Center for International Blood and Marrow Transplant Research (CIBMTR): current uses and outcomes of hematopoietic cell transplants for blood and bone marrow disorders," Clinical Transplantation, pp. 87-105, 2010.

[17] A. Gerbitz, M. Schultz, A. Wilke et al., "Probiotic effects on experimental graft-versus-host disease: let them eat yogurt," Blood, vol. 103, no. 11, pp. 4365-4367, 2004.

[18] Y. Eriguchi, S. Takashima, H. Oka et al., "Graft-versus-host disease disrupts intestinal microbial ecology by inhibiting Paneth cell production of $\alpha$-defensins," Blood, vol. 120, no. 1, pp. 223-231, 2012.

[19] R. R. Jenq, C. Ubeda, Y. Taur et al., "Regulation of intestinal inflammation by microbiota following allogeneic bone marrow transplantation," The Journal of Experimental Medicine, vol. 209, no. 5, pp. 903-911, 2012.

[20] M. H. Fraher, P. W. O’Toole, and E. M. M. Quigley, “Techniques used to characterize the gut microbiota: a guide for the clinician," Nature Reviews Gastroenterology and Hepatology, vol. 9, no. 6, pp. 312-322, 2012.

[21] S. Gu, D. Chen, J.-N. Zhang et al., "Bacterial community mapping of the mouse gastrointestinal tract," PLoS ONE, vol. 8, no. 10, Article ID e74957, 2013.

[22] J. Qin, R. Li, J. Raes et al., "A human gut microbial gene catalogue established by metagenomic sequencing," Nature, vol. 464, no. 7285, pp. 59-65, 2010.

[23] Human Microbiome Project Consortium, "A framework for human microbiome research," Nature, vol. 486, pp. 215-221, 2012.

[24] G. L. Hold, S. E. Pryde, V. J. Russell, E. Furrie, and H. J. Flint, "Assessment of microbial diversity in human colonic samples by $16 \mathrm{~S}$ rDNA sequence analysis," FEMS Microbiology Ecology, vol. 39, no. 1, pp. 33-39, 2002.

[25] E. E. Vaughan, M. C. de Vries, E. G. Zoetendal, K. Ben-Amor, A. D. L. Akkermans, and W. M. De Vos, "The intestinal LABs," Antonie van Leeuwenhoek, vol. 82, no. 1-4, pp. 341-352, 2002.
[26] P. B. Eckburg, E. M. Bik, C. N. Bernstein et al., "Microbiology: diversity of the human intestinal microbial flora," Science, vol. 308, no. 5728, pp. 1635-1638, 2005.

[27] F. Bäckhed, R. E. Ley, J. L. Sonnenburg, D. A. Peterson, and J. I. Gordon, "Host-bacterial mutualism in the human intestine," Science, vol. 307, no. 5717, pp. 1915-1920, 2005.

[28] J. M. Jones, R. Wilson, and P. M. Bealmear, "Mortality and gross pathology of secondary disease in germfree mouse radiation chimeras," Radiation Research, vol. 45, no. 3, pp. 577-588, 1971.

[29] D. W. van Bekkum, J. Roodenburg, P. J. Heidt, and D. van der Waaij, "Mitigation of secondary disease of allogeneic mouse radiation chimeras by modification of the intestinal microflora," Journal of the National Cancer Institute, vol. 52, no. 2, pp. 401404, 1974.

[30] N. Steck, M. Hoffmann, I. G. Sava et al., "Enterococcus faecalis metalloprotease compromises epithelial barrier and contributes to intestinal inflammation," Gastroenterology, vol. 141, no. 3, pp. 959-971, 2011.

[31] E. Holler, P. Butzhammer, K. Schmid et al., "Metagenomic analysis of the stool microbiome in patients receiving allogeneic stem cell transplantation: loss of diversity is associated with use of systemic antibiotics and more pronounced in gastrointestinal graft-versus-host disease," Biology of Blood and Marrow Transplantation, vol. 20, no. 5, pp. 640-645, 2014.

[32] Y. Taur, R. R. Jenq, M.-A. Perales et al., "The effects of intestinal tract bacterial diversity on mortality following allogeneic hematopoietic stem cell transplantation," Blood, vol. 124, no. 7, pp. 1174-1182, 2014.

[33] L. Schwab, L. Goroncy, S. Palaniyandi et al., "Neutrophil granulocytes recruited upon translocation of intestinal bacteria enhance graft-versus-host disease via tissue damage," Nature Medicine, vol. 20, pp. 648-654, 2014.

[34] M. M. Heimesaat, A. Nogai, S. Bereswill et al., "MyD88/TLR9 mediated immunopathology and gut microbiota dynamics in a novel murine model of intestinal graft-versus-host disease," Gut, vol. 59, no. 8, pp. 1079-1087, 2010.

[35] J. M. Vossen, H. F. L. Guiot, A. C. Lankester et al., "Complete suppression of the gut microbiome prevents acute graft-versushost disease following allogeneic bone marrow transplantation," PLoS ONE, vol. 9, no. 9, Article ID e105706, 2014.

[36] R. E. Billingham, "The biology of graft-versus-host reactions," Harvey Lectures, vol. 62, pp. 21-78, 1966.

[37] B. A. Duerkop, S. Vaishnava, and L. V. Hooper, "Immune responses to the microbiota at the intestinal mucosal surface," Immunity, vol. 31, no. 3, pp. 368-376, 2009.

[38] N. Cerf-Bensussan and V. Gaboriau-Routhiau, "The immune system and the gut microbiota: friends or foes?" Nature Reviews Immunology, vol. 10, no. 10, pp. 735-744, 2010.

[39] K. R. Groschwitz and S. P. Hogan, "Intestinal barrier function: molecular regulation and disease pathogenesis," Journal of Allergy and Clinical Immunology, vol. 124, no. 1, pp. 3-20, 2009.

[40] G. R. Hill, J. M. Crawford, K. R. Cooke, Y. S. Brinson, L. Pan, and J. L. M. Ferrara, "Total body irradiation and acute graftversus-host disease: the role of gastrointestinal damage and inflammatory cytokines," Blood, vol. 90, no. 8, pp. 3204-3213, 1997.

[41] R. Noth, J. Lange-Grumfeld, E. Stuber et al., "Increased intestinal permeability and tight junction disruption by altered expression and localization of occludin in a murine graft versus host disease model," BMC Gastroenterology, vol. 11, article 109, 2011. 
[42] P. A. Crawford and J. I. Gordon, "Microbial regulation of intestinal radiosensitivity," Proceedings of the National Academy of Sciences of the United States of America, vol. 102, no. 37, pp. 13254-13259, 2005.

[43] R. M. Jones, V. M. Sloane, H. Wu et al., "Flagellin administration protects gut mucosal tissue from irradiation-induced apoptosis via MKP-7 activity," Gut, vol. 60, no. 5, pp. 648-657, 2011.

[44] P. Delia, G. Sansotta, V. Donato et al., "Use of probiotics for prevention of radiation-induced diarrhea," World Journal of Gastroenterology, vol. 13, no. 6, pp. 912-915, 2007.

[45] F. Yan, L. Liu, P. J. Dempsey et al., "A lactobacillus rhamnosus GG-derived soluble protein, p40, stimulates ligand release from intestinal epithelial cells to transactivate epidermal growth factor receptor," Journal of Biological Chemistry, vol. 288, no. 42, pp. 30742-30751, 2013.

[46] C. L. Bevins and N. H. Salzman, "Paneth cells, antimicrobial peptides and maintenance of intestinal homeostasis," Nature Reviews Microbiology, vol. 9, no. 5, pp. 356-368, 2011.

[47] T. Ayabe, D. P. Satchell, C. L. Wilson, W. C. Parks, M. E. Selsted, and A. J. Ouellette, "Secretion of microbicidal $\alpha$ defensins by intestinal Paneth cells in response to bacteria," Nature Immunology, vol. 1, no. 2, pp. 113-118, 2000.

[48] J. E. Levine, E. Huber, S. T. G. Hammer et al., "Low Paneth cell numbers at onset of gastrointestinal graft-versus-host disease identify patients at high risk for nonrelapse mortality," Blood, vol. 122, no. 8, pp. 1505-1509, 2013.

[49] O. Penack, E. Holler, and M. R. M. van den Brink, "Graft-versushost disease: regulation by microbe-associated molecules and innate immune receptors," Blood, vol. 115, no. 10, pp. 1865-1872, 2010.

[50] S. Akira and K. Takeda, "Toll-like receptor signalling," Nature Reviews Immunology, vol. 4, no. 7, pp. 499-511, 2004.

[51] A. Hidmark, A. von Saint Paul, and A. H. Dalpke, "Cutting edge: TLR13 is a receptor for bacterial RNA," Journal of Immunology, vol. 189, no. 6, pp. 2717-2721, 2012.

[52] N. Inohara, Y. Ogura, F. F. Chen, A. Muto, and G. Nuñez, "Human Nodl confers responsiveness to bacterial lipopolysaccharides," The Journal of Biological Chemistry, vol. 276, no. 4, pp. 2551-2554, 2001.

[53] C. Calcaterra, L. Sfondrini, A. Rossini et al., "Critical role of TLR9 in acute graft-versus-host disease," Journal of Immunology, vol. 181, no. 9, pp. 6132-6139, 2008.

[54] E. Lorenz, D. A. Schwartz, P. J. Martin et al., "Association of TLR4 mutations and the risk for acute GVHD after HLAmatched-sibling hematopoietic stem cell transplantation," Biology of Blood and Marrow Transplantation, vol. 7, no. 7, pp. 384387, 2001.

[55] T. Imado, T. Iwasaki, S. Kitano et al., "The protective role of host Toll-like receptor-4 in acute graft-versus-host disease," Transplantation, vol. 90, no. 10, pp. 1063-1070, 2010.

[56] C. Skert, M. Fogli, S. Perucca et al., "Profile of Toll-like receptors on peripheral blood cells in relation to acute graft-versus-host disease after allogeneic stem cell transplantation," Biology of Blood and Marrow Transplantation, vol. 19, no. 2, pp. 227-234, 2013.

[57] J. L. Cohen and O. Boyer, "The role of $\mathrm{CD} 4^{+} \mathrm{CD} 25^{\text {hi }}$ regulatory T cells in the physiopathogeny of graft-versus-host disease," Current Opinion in Immunology, vol. 18, no. 5, pp. 580-585, 2006.

[58] P. Ratajczak, A. Janin, R. P. de Latour et al., "Th17/Treg ratio in human graft-versus-host disease," Blood, vol. 116, no. 7, pp. 11651171, 2010.
[59] T. Yi, D. Zhao, C.-L. Lin et al., "Absence of donor Th17 leads to augmented Th1 differentiation and exacerbated acute graftversus-host disease," Blood, vol. 112, no. 5, pp. 2101-2110, 2008.

[60] M. J. Carlson, M. L. West, J. M. Coghill, A. Panoskaltsis-Mortari, B. R. Blazar, and J. S. Serody, "In vitro differentiated TH17 cells mediate lethal acute graft-versus-host disease with severe cutaneous and pulmonary pathologic manifestations," Blood, vol. 113, no. 6, pp. 1365-1374, 2009.

[61] L. W. Kappel, G. L. Goldberg, C. G. King et al., "IL-17 contributes to CD4-mediated graft-versus-host disease," Blood, vol. 113, no. 4, pp. 945-952, 2009.

[62] C. I. Kingsley, M. Karim, A. R. Bushell, and K. J. Wood, "CD $25^{+} \mathrm{CD} 4^{+}$regulatory $\mathrm{T}$ cells prevent graft rejection: CTLA4- and IL-10-dependent immunoregulation of alloresponses," Journal of Immunology, vol. 168, no. 3, pp. 1080-1086, 2002.

[63] K. Honda and D. R. Littman, "The microbiome in infectious disease and inflammation," Annual Review of Immunology, vol. 30, pp. 759-795, 2012.

[64] I. I. Ivanov and K. Honda, "Intestinal commensal microbes as immune modulators," Cell Host and Microbe, vol. 12, no. 4, pp. 496-508, 2012.

[65] S. Z. Josefowicz, L.-F. Lu, and A. Y. Rudensky, "Regulatory T cells: mechanisms of differentiation and function," Annual Review of Immunology, vol. 30, pp. 531-564, 2012.

[66] K. M. Nutsch and C.-S. Hsieh, "T cell tolerance and immunity to commensal bacteria," Current Opinion in Immunology, vol. 24, no. 4, pp. 385-391, 2012.

[67] T. Korn, E. Bettelli, M. Oukka, and V. K. Kuchroo, "IL-17 and Th17 cells," Annual Review of Immunology, vol. 27, pp. 485-517, 2009.

[68] J. A. Hall, N. Bouladoux, C. M. Sun et al., "Commensal DNA limits regulatory $\mathrm{T}$ cell conversion and is a natural adjuvant of intestinal immune responses," Immunity, vol. 29, no. 4, pp. 637649, 2008.

[69] B. He, W. Xu, P. A. Santini et al., "Intestinal bacteria trigger $\mathrm{T}$ cell-independent immunoglobulin A (2) class switching by inducing epithelial-cell secretion of the cytokine APRIL," Immunity, vol. 26, no. 6, pp. 812-826, 2007.

[70] K. Atarashi, T. Tanoue, K. Oshima et al., “Treg induction by a rationally selected mixture of Clostridia strains from the human microbiota," Nature, vol. 500, no. 7461, pp. 232-236, 2013.

[71] V. Gaboriau-Routhiau, S. Rakotobe, E. Lécuyer et al., "The key role of segmented filamentous bacteria in the coordinated maturation of gut helper T cell responses," Immunity, vol. 31, no. 4, pp. 677-689, 2009.

[72] I. I. Ivanov, K. Atarashi, N. Manel et al., "Induction of intestinal Th17 cells by segmented filamentous bacteria," Cell, vol. 139, no. 3, pp. 485-498, 2009.

[73] J. S. Serody and T. C. Shea, "Prevention of infections in bone marrow transplant recipients," Infectious Disease Clinics of North America, vol. 11, no. 2, pp. 459-477, 1997.

[74] H. Goossens, M. Ferech, R. Vander Stichele, and M. Elseviers, "Outpatient antibiotic use in Europe and association with resistance: a cross-national database study," The Lancet, vol. 365, no. 9459 , pp. 579-587, 2005.

[75] E. R. Dubberke, K. A. Reske, M. A. Olsen, L. C. McDonald, and V. J. Fraser, "Short- and long-term attributable costs of Clostridium difficile-associated disease in nonsurgical inpatients," Clinical Infectious Diseases, vol. 46, no. 4, pp. 497-504, 2008. 
[76] C. P. Kelly and J. T. LaMont, "Clostridium difficile-more difficult than ever," The New England Journal of Medicine, vol. 359, no. 18, pp. 1932-1940, 2008.

[77] S. Chakrabarti, A. Lees, S. G. Jones, and D. W. Milligan, "Clostridium difficile infection in allogeneic stem cell transplant recipients is associated with severe graft-versus-host disease and non-relapse mortality," Bone Marrow Transplantation, vol. 26, no. 8, pp. 871-876, 2000.

[78] L. J. Brandt and O. C. Aroniadis, "An overview of fecal microbiota transplantation: techniques, indications, and outcomes," Gastrointestinal Endoscopy, vol. 78, no. 2, pp. 240-249, 2013.

[79] T. J. Borody, S. Paramsothy, and G. Agrawal, "Fecal microbiota transplantation: a new standard treatment option for Clostridium difficile infection," Current Gastroenterology Reports, vol. 15, article 337, 2013.

[80] J. De Vrieze, “The promise of poop," Science, vol. 341, no. 6149, pp. 954-957, 2013.

[81] E. O. Petrof and A. Khoruts, "From stool transplants to nextgeneration microbiota therapeutics," Gastroenterology, vol. 146, no. 6, pp. 1573-1582, 2014.

[82] S. Doron and S. L. Gorbach, "Probiotics: their role in the treatment and prevention of disease," Expert Review of AntiInfective Therapy, vol. 4, no. 2, pp. 261-275, 2006.

[83] M. E. Sanders, F. Guarner, R. Guerrant et al., "An update on the use and investigation of probiotics in health and disease," Gut, vol. 62, no. 5, pp. 787-796, 2013.

[84] A. C. Ouwehand, S. Salminen, and E. Isolauri, "Probiotics: an overview of beneficial effects," Antonie van Leeuwenhoek, vol. 82, no. 1-4, pp. 279-289, 2002.

[85] P. Österlund, T. Ruotsalainen, R. Korpela et al., "Lactobacillus supplementation for diarrhoea related to chemotherapy of colorectal cancer: a randomised study," British Journal of Cancer, vol. 97, no. 8, pp. 1028-1034, 2007.

[86] N. Li, W. M. Russell, M. Douglas-Escobar, N. Hauser, M. Lopez, and J. Neu, "Live and heat-killed Lactobacillus rhamnosus GG: effects on proinflammatory and anti-inflammatory cytokines/chemokines in gastrostomy-fed infant rats," Pediatric Research, vol. 66, no. 2, pp. 203-207, 2009.

[87] L. Khailova, B. Petrie, C. H. Baird, J. A. Dominguez Rieg, and P. E. Wischmeyer, "Lactobacillus rhamnosus GG and Bifidobacterium longum attenuate lung injury and inflammatory response in experimental sepsis," PLoS ONE, vol. 9, no. 5, Article ID e97861, 2014.

[88] S. Lebeer, J. Vanderleyden, and S. C. J. De Keersmaecker, "Host interactions of probiotic bacterial surface molecules: comparison with commensals and pathogens," Nature Reviews Microbiology, vol. 8, no. 3, pp. 171-184, 2010.

[89] P. A. Bron, P. Van Baarlen, and M. Kleerebezem, "Emerging molecular insights into the interaction between probiotics and the host intestinal mucosa," Nature Reviews Microbiology, vol. 10, no. 1, pp. 66-78, 2012.

[90] L. O’Mahony, J. McCarthy, P. Kelly et al., "Lactobacillus and Bifidobacterium in irritable bowel syndrome: symptom responses and relationship to cytokine profiles," Gastroenterology, vol. 128, no. 3, pp. 541-551, 2005.

[91] S. J. Allen, E. G. Martinez, G. V. Gregorio, and L. F. Dans, "Probiotics for treating acute infectious diarrhoea," Cochrane Database of Systematic Reviews, no. 11, Article ID CD003048, 2010.

[92] C. Manichanh, N. Borruel, F. Casellas, and F. Guarner, "The gut microbiota in IBD," Nature Reviews Gastroenterology and Hepatology, vol. 9, no. 10, pp. 599-608, 2012.
[93] C. Vanderpool, F. Yan, and D. B. Polk, "Mechanisms of probiotic action: implications for therapeutic applications in inflammatory bowel diseases," Inflammatory Bowel Diseases, vol. 14, no. 11, pp. 1585-1596, 2008.

[94] W. Kruis, P. Frič, J. Pokrotnieks et al., "Maintaining remission of ulcerative colitis with the probiotic Escherichia coli Nissle 1917 is as effective as with standard mesalazine," Gut, vol. 53, no. 11, pp. 1617-1623, 2004.

[95] T. Mimura, F. Rizzello, U. Helwig et al., "Once daily high dose probiotic therapy (VSL\#3) for maintaining remission in recurrent or refractory pouchitis," Gut, vol. 53, no. 1, pp. 108$114,2004$.

[96] S. Prakash, C. Tomaro-Duchesneau, S. Saha, and A. Cantor, "The gut microbiota and human health with an emphasis on the use of microencapsulated bacterial cells," Journal of Biomedicine and Biotechnology, vol. 2011, Article ID 981214, 12 pages, 2011.

[97] L. A. David, C. F. Maurice, R. N. Carmody et al., "Diet rapidly and reproducibly alters the human gut microbiome," Nature, vol. 505, no. 7484, pp. 559-563, 2014.

[98] L. Dethlefsen, S. Huse, M. L. Sogin, and D. A. Relman, "The pervasive effects of an antibiotic on the human gut microbiota, as revealed by deep 16s rRNA sequencing," PLoS Biology, vol. 6, no. 11, article e280, 2008. 


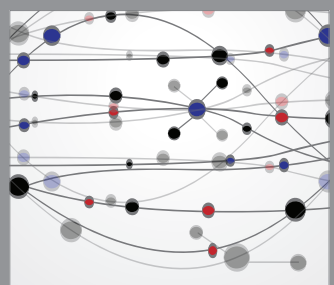

The Scientific World Journal
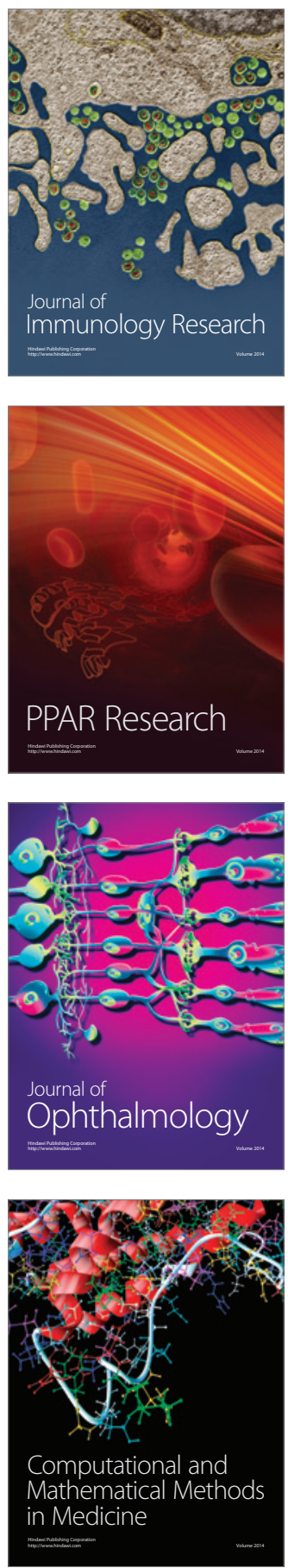

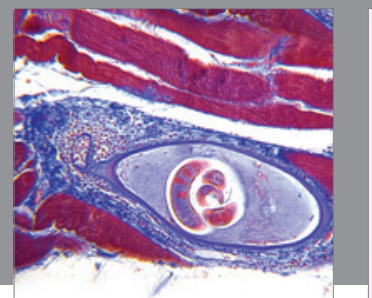

Gastroenterology

Research and Practice
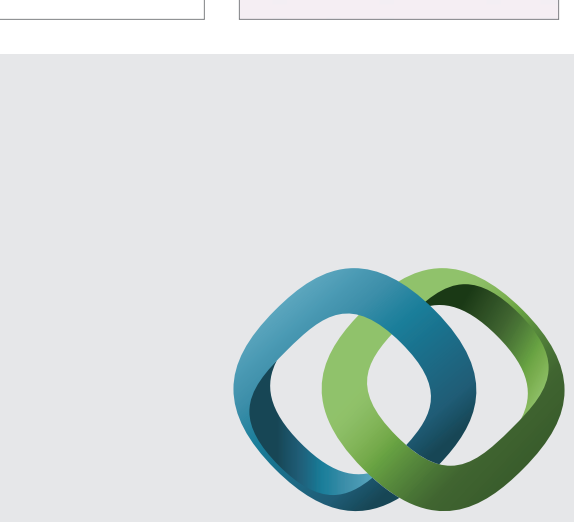

\section{Hindawi}

Submit your manuscripts at

http://www.hindawi.com
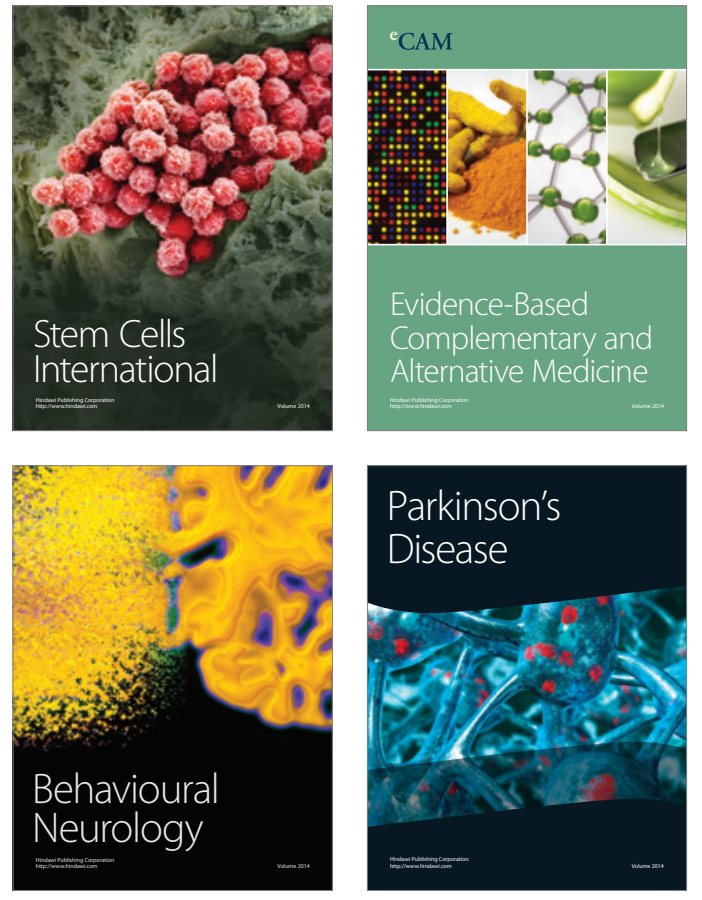
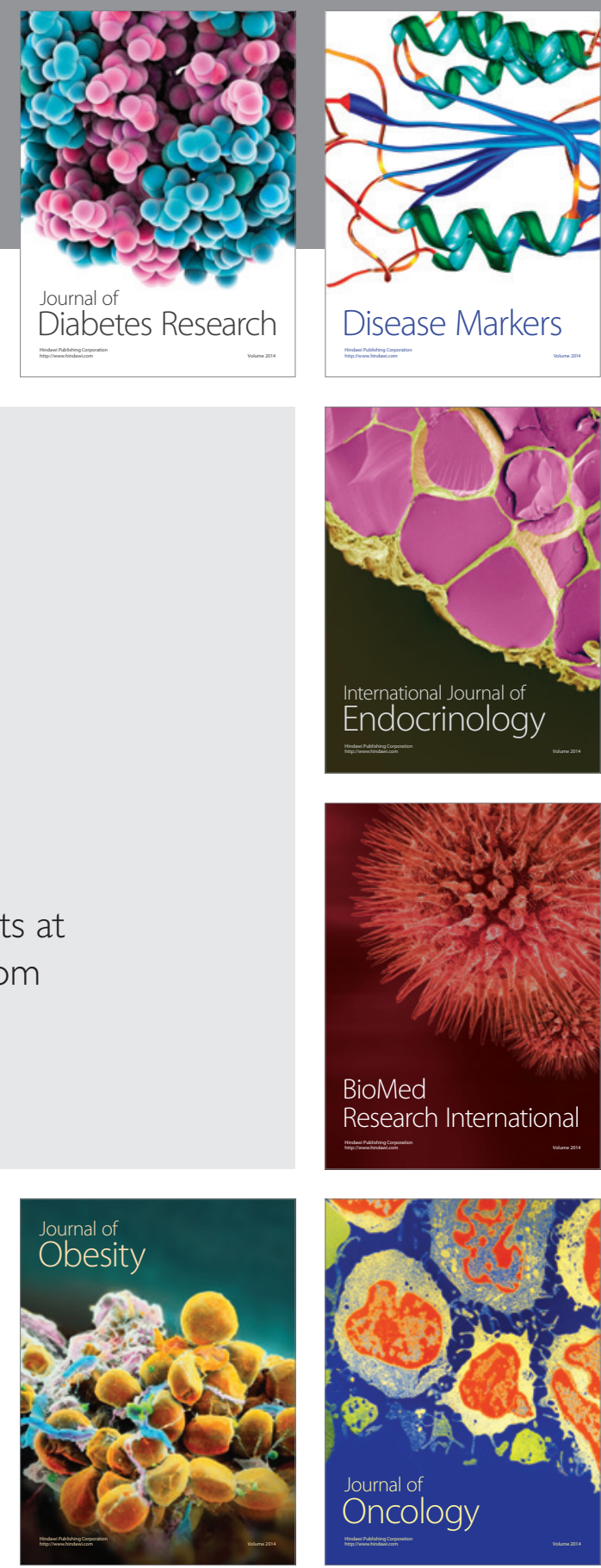

Disease Markers
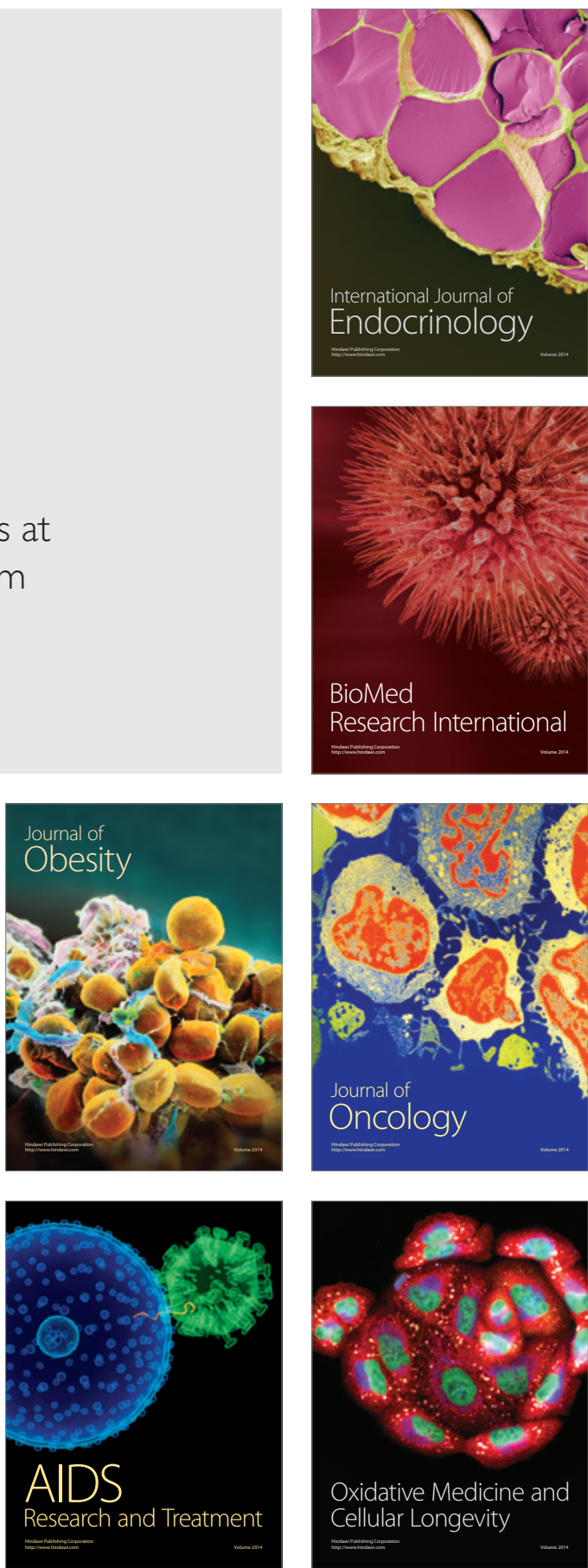